\title{
Dramaturgia do invisível, dramaturgia do possível, dramaturgia da imanência: apontamento para uma potente dramaturgia microscópica \\ Patricia Leonardelli ${ }^{1}$ \\ Renato Ferracini ${ }^{2}$
}

Resumo

O presente texto discute a produção da palavra e do texto escrito em processos de criação performativos a partir da noção de palavra não como signo arbitrário e decalque, mas como atualização-em- potência dentro de mapas de linguagem construídos nos planos específicos de composição de cada programa performativo.

Palavras chave: dramaturgia; invisibilidade; corpo; memória; texto

This paper discusses the production of word and written text in performative creation processes based on the notion of word not as an arbitrary sign and decal, but as an uptade-in-power inside the maps of language that are built in which specific performative program's plan of composition.

Keywords: dramaturgy; invisibility;

body; memory; text

\footnotetext{
1 Desenvolve sua pesquisa de pós-doutorado vinculada ao Projeto Temático "Memória(s) e Pequenas Percepções" com o grupo LUME, na Unicamp (Campinas, SP). Tem doutorado em Artes pela Universidade de São Paulo (2008). Em 2000, estudou treinamento expressivo com o Grupo Odin Teatret (Holstebro, Dinamarca), objeto central de sua pesquisa profissional desde então. É atriz e professora. Sua experiência é na área de Artes Cênicas, com ênfase em Interpretação Teatral, atuando principalmente nos seguintes temas: ator, teatro, interpretação, memória, movimento, criação, improvisação, dança, teatro e circo.

2 Tem doutorado (2004) em Multimeios pela Unicamp. É ator-pesquisador e atualmente Coordenador do LUME - Núcleo interdisciplinar de Pesquisas Teatrais da UNICAMP onde atua teórica/praticamente em todas as linhas de pesquisa do núcleo desde 0 ano de 1993. É professor e orientador no Programa de Pós-Graduação em Artes da Cena Hoje coordena o Projeto Temático Fapesp "Memória(s) e Micropercepção" e é Bolsista de Produtividade do CNPQ. Possui três livros publicados: "AArte de Não Interpretar como Poesia Corpórea do Ator" (Editora da Unicamp e FAPESP - 2001), "Café com Queijo: Corpos em Criação" (Hucitec e Fapesp - 2006) e "Corpos em Fuga, Corpos em Arte - ORG" (Hucitec e Fapesp - 2006).
} 
A pesquisa avançada sobre dramaturgia se desenvolve, atualmente, mais ou menos alinhada a um ou outro dos dois principais eixos de tradição crítica: a alemã e a francesa. Eixos que, é sabido, se provocam e alimentam, movimentando o debate sobre um território onde a pletora de produções exige o esforço permanente de conceituação/contenção das experiências a fim de que a própria disciplina não se esvazie pela falta de fronteiras e de tradução. É, em grande parte, pela interlocução entre as duas vertentes de estudo que vem se estruturando algumas potentes matrizes teórico-conceituais para uma possível ontologia da dramaturgia contemporânea (se não for ambicioso demais conjecturar tal campo), sustentada pela análise da evolução da disciplina desde 1880. Tal debate serve-nos, particularmente, pelo esforço em fixar, com consistência e rigor, seu âmbito e suas singularidades dinâmicas, com o qual as demais fronteiras de pensamento sobre a ação teatral podem dialogar.

Em um platô de reflexão, está a tradição alemã, cuja orientação se substancializa com as produções (teórico-pedagógicas) de Brecht e (teórica) de Peter Szondi, mas profundamente tributária, quanto a seus desenhos filosóficos, da teoria adorniana, e que se atualiza, na contemporaneidade, pelo estatuto do pós-dramático de Hans Thies-Lehmann. Evidentemente, não se trata de um pensamento sucessivo (ainda que notoriamente Lehmann tenha sido aluno de Szondi), mas da estruturação de uma perspectiva dialética de autosuperação da dramaturgia como força de produção, que teria experimentado com as inovadoras operações do teatro épico de Brecht o instante aglutinador/revolucionário de síntese máxima diante da crise do drama, que já se anunciava nas primeiras décadas do século passado.

A partir de Brecht, conforme Szondi e Lehmann, irrompe-se mais radicalmente o campo de experimentação quanto à exploração das possibilidades de criação de texto e cena para além dos enunciados do drama, que resultaria na enorme diversidade de produções e processos atuais, as quais Lehmann reúne sob o guardachuva conceitual do pós-dramático. Não obstante, salientemos, se for ainda necessário, que tal irrupção resulta menos de um possível hedonismo estético pelo exercício formal historicamente localizado, e mais da crise global das artes e, em grande parte, também das humanidades em geral, de reconhecimento do sujeito histórico e de suas macro e micro relações na modernidade. Diante do suposto "eu desintegrado" moderno, a lógica unificante e sintética do projeto dramático já não forneceria estruturas / ferramentas de tradução que comportassem a multiplicidade de vozes, planos, olhares, deslocamentos desse homem em fragmentos, alienado da natureza e apartado de seus semelhantes e de Deus.

O teatro pós-dramático se apresenta, assim, como um paradoxo gênero/nãogênero, que abarcaria todo teatro que escapa ao primado da ação-imitação, da ilusão de reprodução do real, e a consequente construção de um texto e de uma cena cuja mimese busca a totalidade e o fechamento de sentidos, bem como de seus modelos de produção. $\mathrm{Na}$ análise de Lehmann, o discurso dramático, por sua tendência unívoca, entre outros componentes, fora, irremediavelmente, capturado pela indústria cultural, e trabalha, hoje, a favor exclusivamente de seus interesses. Portanto, por sua raiz original épica, da qual derivariam as demais rupturas historicamente subsequentes, o teatro pós-dramático carregaria per se, pela simples refutação aos esquemas dramáticos, um realinhamento político (logo, formal, posto que desde Barthes não se pode pensar em outra ação política para o teatro senão por uma que perpasse sua construção estética) de resistência e oposição à apropriação da forma dramática pela cultura de massa, e sua servidão, como linguagem, aos discursos da maquinaria que lhe investe, independentemente da configuração que assumisse. 
Em lugar distinto, se localiza a crítica francesa, representada, em nossa seleção, pelos trabalhos, já bastantes difundidos, do Grupo de Pesquisas sobre a Poética do Drama Moderno e Contemporâneo, coordenado por Jean-Pierre Sarrazac. Escolhemos tal coletivo, fundamentalmente, porque suas investigações assumem a crise do drama como apresentada por Szondi (em sua obra de referência Teoria do drama moderno, 1954), mas se propõem a refletir sobre essa crise não só por outros referenciais teórico-filosóficos, mas com um outro "espírito", por assim dizer; qual seja, de evitar, ou ao menos recuar, na anulação-superação imediata a que o gênero dramático está condenado na análise dialética do pós-dramático.

Tal crítica reconhece todo impacto do trabalho de Brecht na evolução da dramaturgia universal, e não exclui a influência de sua produção em toda cena ulterior. Porém, não compreende o movimento do teatro moderno numa perspectiva, de certa forma, teleológica, em que a forma pósdramática seria uma síntese/superação do drama alavancada pelo épico, como sugere a obra de Lehmann. Para Sarrazac e sua equipe, as questões levantadas pela crise do drama foram sendo respondidas simultaneamente por uma série de dramaturgos (Ibsen, Strindberg, Tchekov, Adamov, Maeterlink) em suas obras, que novamente levantam uma nuvem problemática, numa crise sem fim (contrariamente a Lehmann que veria a história das poéticas teatrais como o progresso de uma forma para a outra, resultantes da resolução parcial da crise do drama).

O teatro e a teatralidade se instauram nessa crise que esvazia incessantemente o estatuto anterior do teatro em si, e abre espaço para novas dramaturgias, processos e teatralidades específicas. A resolução fundaria um novo teatro, ou imporia uma progressão do teatro, premissa de que Sarrazac desconfia, preferindo investir na noção de dramaturgia como, precisamente, o produto não dado e em permanente construção pelas demandas do contemporâneo. Como se o teatro (e sua crise) operasse mais numa dinâmica multilinear de respostas para as questões da crise do drama do que no caminho de uma única solução. Trata-se de um campo de sínteses múltiplas, que se contaminam, e cujas novas formas não fazem outra coisa senão preencher para imediatamente esvaziar o quer poderia se tornar a essência de um novo teatro para além do drama. Assim, o drama não precisa ser abandonado, pois não funciona mais como uma categoria desgastada, uma roupa velha à qual tentam, forçosamente, embutir um corpo novo. Ele se reconfigura como um espaço de ampla recriação, cujos desdobramentos formais só fazem revelar as possibilidades transgressoras e atuais que o gênero ainda contém.

Dessa forma, como já apontamos, a crítica francesa abarca e partilha dos mesmos princípios de identificação da crise do drama levantados pelos teóricos alemães (a separação do homem de seus agregadores identitários, solidão e polifonia existencial, apartamento do divino, etc. que demandariam outro tipo de relato dramático), mas busca na observação mais ampla das respostas artísticas oferecidas pela produção histórica dos dramaturgos em seus projetos singulares os encaminhamentos teóricos para tais questões.

Nessa perspectiva, um conceito específico emerge de forma particularmente potente. Em seu pequeno texto O Jogo dos Possíveis ${ }^{3}$, Sarrazac introduz o termo dramaturgia dos possíveis, em um contexto de reflexão que nos parece particularmente ampliado sobre a criação dramatúrgica. Ao passo que postula a dramaturgia como um território em crise permanente, crise de soluções provisórias que inauguram novas crises que abrem novos espaços de solução, que não são outras senão as próprias produções dramatúrgicas e toda diversidade como reconhecemos na cena contemporânea, o pensamento Sarrazac nos oferece a possibilidade de pen-

3 Jean-Pierre Sarrazac, "O Jogo dos Possíveis", in: A Invenção da Teatralidade, p. 81-83, trad. Alexandra Moreira da Silva. Porto: Deriva, 2009. 
sar cada experiência dramatúrgica como um referencial em si. Um referencial que pode se criar para além do enquadramento exterior entre gêneros e ser produzido mediante as linhas de força intrínsecas ao processo de criação (livres, da demanda apriorística de se localizar no campo do dramático, do pós-dramático, do lírico, etc).

Assim, interessa menos tentar redefinir as fronteiras de um novo gênero, buscando fixar possíveis elementos comuns de reconhecimento que permitiriam identificar tais experiências, do que assumir a diversidade não mais como "pletora", mas como "território de multiplicidades". Não refutamos a potência, o rigor e alcance da crítica de Lehmann, especialmente quando detalha os procedimentos de apropriação das operações do drama pela máquina da cultura de massa. Porém, nos parece um pouco forçoso considerar que apenas a forma dramática foi transfigurada pelos agenciamentos nefastos da sociedade das mercadorias, e que, escapando do drama, o teatro empreenderia, per se, uma atitude de resistência política. A revolução está em outro lugar, um lugar que já existe, e que, paradoxalmente, está por construir.

Voltemos a uma noção mais geral de dramaturgia. Há uma imagem consideravelmente comum e amplamente aceita de dramaturgia na teoria da cena contemporânea, que vem fundamentalmente, e Barba e da Antropologia Teatral: a de uma tessitura. Essa imagem metafórica apresenta a dramaturgia como o entrelaçamento dos elementos cênicos macroscópicos (música, atores, cenários, figurinos, texto, mídias, disposição do público, etc) que por meio de seus encontros geram tensões, relaxamentos, buracos, saltos, desvios e assim proporcionam um TECIDO, uma TESSITURA em multiplicidade complexa. Esse tecido (ou tecidos) dinâmico flutuante gerado por tais linhas-cênicas, deitadas sobre o tecido complexo do espaço-tempo (que também pode ser agenciado como uma linha de opção dra- matúrgica) gera o que podemos chamar de dramaturgia cênica. Podemos dizer que optar por uma dramaturgia-tecido pensada dessa forma abre espaço para novos encontros e posturas em relação ao próprio fazer cênico:

Concretude do material: as linhas, cada uma delas, oferecem uma matéria concreta de atuação, e cada qual também possui a complexidade e multiplicidade semântica e sígnica flutuante já bastante potente em si. Por exemplo, o corpo do ator - enquanto linha de tessitura - já possui em si mesmo - uma multiplicidade complexa de afetos e signos flutuantes com sua técnica e trabalho corporal específico. O mesmo se pode dizer da potência plástica do figurino com as cores e formas que possuem. O encontro concreto - somente como exemplo - do ator com o figurino já gera - somente nessas duas linhas - tensões e potências infinitas de agenciamentos.

Liberdade de opção de material: há uma liberdade criativa na escolha das linhas que farão parte da ação cênica (seja ela teatro, dança, performance ou qualquer outra). Não há uma linha necessária ou suficiente para realizar a trama. Cada linha do tecido cênico pode ser suprimida ou mesmo linhas outras podem ser incluídas abrindo-se aí um leque de potencialidade criativa cênica praticamente infinita.

Isonomia necessária de material: enquanto tecido (formado pela ação ativa do tecer das linhas-cênicas) descarta-se qualquer centro hierárquico, ou seja, não pode haver dentre as opções qualquer linha que venha a ser a principal do tecido, mesmo que essa linha "optada" pelo criador cênico venha a ser de uma cor ou textura diferenciada. Todo o conjunto de linhas agrupadas enquanto opção são igualmente importantes para a ação do tecer, ou do fazer o tecido dramatúrgico.

A concretude, liberdade de opção e isonomia do material-linha a ser tecido na dramaturgia contemporânea maximizam em muito as formas de experimentação 
cênica e, de certa forma, proporcionam uma grande dor de cabeça nos conservadores do purismo de linguagem. Pode-se criar uma dramaturgia sem texto, mas também sem atores - alguns espetáculos dadaístas não possuíam atores. Sem espaço físico - vários são os espetáculos realizados na internet com atores de países diferentes que fazem personagens diferentes; estes substituem o espaço físico por um espaço virtual. Sem público - Grotowski no final de sua vida abdicou da audiência para realizar experimentações práticas com atores e atrizes em um espaço fechado localizado em PontederaItália. Pina Bauch inclui o texto na dança e tece outra potência hoje chamada de dança-teatro, além de se fazer muito comum hoje pensar em uma dramaturgia da dança que - quando pensada em termos de tessitura - se faz bastante coerente e potente enquanto novo lócus de investigação. Muitos seriam os exemplos atuais e recentes dessa postura dramatúrgica em tessitura mas paro por aqui.

O tecido em dramaturgia também proporciona hibridismos, fusões, invasões e toques de linhas que delimitam as várias linguagens e áreas artísticas. Esse movimento explode e implode as linguagens e assim gera outras formas de criação, o que amplia em muito o que Dickie (1976) chama de "O Mundo da Arte".

Mas podemos e devemos ir um pouco além do tecido e da tessitura mesmo verificando o quanto de potência positiva e bons encontros essa nova postura "dramatúrgica em tessitura" provocou e proporcionou no mundo da arte cênica até agora. Acreditamos que a dramaturgia em tessitura ainda propõe - enquanto conceito, imagem, metáfora e teoria uma imagem por demais organizada. Um “tecido dramatúrgico" pode ser também visto como uma organização extremada de fios que se moldam com uma finalidade específica. Isso pode levar à ideia que de existe uma certa maneira específica de organização desse tecido dramatúrgico e mesmo uma certa teleologia de fundo ou mesmo intencionalidade objetiva, mesmo que as liberdades criativas que essa ideia proporciona seja bastante potente. Para além disso, as linhas organizadas do tecido podem - erroneamente - serem vistas como linhas macroscópicas: uma "matéria simples", objetivada. Ora, sabemos que a presença - mesmo complexa - ou mesmo a simples organização dessas linhas em nada garante a qualidade e a potência do tecido dramatúrgico contemporâneo enquanto força estética. Não é pelo simples mesclar ou inventar novas linhas ou ainda o fato de gerar novas formas de compilação desse tecido organizativo que essa potência estética se garanta; ou seja, não é tendo "brilhantes ideias" de supressões de linhas ou "puras intuições" de inclusões, ou "grandes experimentações" de organização do tecido dramatúrgico que a potência estética esteja garantida.

A matéria e a concretude dessas linhas não podem somente serem pensadas como um "material objetivo". A materialidade contemporânea supõe, ou deveria supor, que a concretude passa não somente pela objetividade da matéria, mas principalmente pelas forças que agem sobre ela. Essas forças, apesar de não serem "matéria" possuem, certamente, uma certa concretude e materialidade. A forma estética - ou no nosso caso específico desse estudo - a dramaturgia - gera o que José Gil chama de "formas de força" (Gil) e não simplesmente uma forma objetivada. Ao buscar "jogar" e agenciar o tecido dramatúrgico com essas forças podemos gerar então uma TEXTURA dramatúrgica (Ramos, 2009) ${ }^{4}$. A textura dramatúrgica seria então, o tecido dramatúrgico atravessado pelas forças que sua concretude gera. Enquanto a tessitura pressupõe organização e mesmo uma teleologia a textura propõe uma certa tatilidade (Ferral) como matéria-material concreto que vaza da organização linhas-

$4 \mathrm{~A}$ imagem de Textura Dramatúrgica me foi apresentada pela primeira vez pelo pesquisador e amigo Prof. Dr. Luis Fernando Ramos da USP, em uma palestra proferida na III Jornada Latinoamericana de Teatro - Florianópolis - em 2009. 
força da dramaturgia. A dramaturgia secreta texturas. Mas o que seria essa materialidade das linhas-força que não se reduz a matéria, mas forma uma textura dramatúrgica?

O próprio fundador da Poética nos alerta em sua obra de fundação: não é ofício do poeta narrar o que aconteceu; é sim, o de representar o que poderia acontecer, quer dizer, o que é possível segundo a verossimilhança e a necessidade. O possível, como categoria que acolhe pelo dito, o não-dito, imediatamente. A palavra não mais como unidade que encerra o sentido, mas como atualização que carrega em potência todo um campo de possíveis significações. Às palavras de Sarrazac:

Se ainda for permitido <sonhar com o que está para vir>, eu avançaria a hipótese de que o teatro é o lugar da invenção dos possíveis; de que os possíveis representam o horizonte utópico no qual se desenham as dramaturgias de nossos dias. [...] Sem pretender abrir o debate filosófico sobre esta categoria do possível, notemos que o possível ao qual nos referimos não é um possível pré-existente, um possível idealista os normativo, que ele não está contido neste "armário dos possíveis", de que se ri Bergson. Para nós, como para Bergson, $<$ é o real que faz o possível, e não o possível que se torna real $>$. Através do jogo teatral dos possíveis, tentarse-á surpreender não tanto um mundo fixo, preso a uma aritmética rígida dos possíveis, mas muito mais a $<$ originalidade instável das coisas $>\mathrm{e}$ $0<$ jacto efectivo da novidade imprevisível>. Mais, do que ao possível, o jogo que nós vamos tentar evocar está ligado ao virtual, no sentido que lhe dá Artaud quando fala do teatro como <realidade virtual $>$.[...] Desde $\log 0$, o acto teatral não consistirá tanto em selecionar possíveis previamente existentes, mas muito mais em multiplicar e fazer fugir à sua frente, sob efeito de uma constante diferenciação, estes < possíveis virtuais> que ele cria constantemente. (Sarrazac, 2009, p. 76-77).
A potência do texto extrapola e se emancipa radicalmente do enunciado. Não pensamos mais em termos da "ambiguidade" ou "sugestão" de um texto que, buscando uma abertura de sentidos pelos mais diversos estratagemas formais, possa suscitar movimentos vários na imaginação do espectador, mas de conceber todo um estatuto para a invisibilidade da palavra, e quais condições de produção definem a singularidade da atualização como apresentada por Sarrazac no parágrafo acima. Conforme intui o pesquisador, compreender a invisibilidade da palavra como instância de significação tão real e potente do texto quanto sua articulação visível, requer que nos apoiemos em todo um entorno teórico que sustente tamanha especulação, pois de outra forma não é possível sequer imaginar tais movimentos.

Nessa perspectiva, a dramaturgia migra, necessariamente, do plano da semiótica clássica para aquele da composição, conforme definido por Deleuze. O texto ganha sentido pela atualização possível, mas também desejável, no jogo de alinhamento das forças envolvidas em cada forma de produção; para, imediatamente, desdobrar um campo singular de virtuais para novos trânsitos, sucessivamente. A palavra ou texto como pontos possíveis de materialização de sentidos que não se abrem para outros sentidos específicos, por denotação, conotação, o ou que outra operação desejarmos, mas para toda a multiplicidade como "errância", cuja plasticidade dos agenciamentos não se encaixa mais nas estruturas linguísticas já mapeadas.

Cada produção dramatúrgica, atualmente, inaugura todo um campo específico da disciplina em si. Se até mais ou menos o período da crise do drama, cuja data referenciada pelos teóricos aqui levantados, para efeito de estudo, se localiza em volta de 1880, o trabalho autônomo do dramaturgo e as escolas e tradições ao qual se filiava permitiam identificar um território estético comum de experimen- 
tação, a partir de Brecht e dos mecanismos do teatro épico, e nisso concordamos com ambos os autores, inaugura-se outra forma de escrita para cena, que supera (numa perspectiva não-teleológica) os gêneros e subgêneros clássicos. Um panorama que exige que se pense a dramaturgia para além da dramaturgia nos seus limites disciplinares, e que passe, fundamentalmente, nos parece, por uma análise outra sobre a invisibilidade da palavra.

Toda palavra carrega em si uma espécie de conteúdo selvagem, pré-pós-linguagem, que torna o texto tão mais rico quanto melhor compreende essa instância como linha de fuga da molaridade "texto". Jogando com a "selvageria dos sentidos", e tomando tais atravessamentos não como desvios de linguagem, mas como parte fundamental da natureza da palavra, o texto surge como território da crise, e não da resolução, campo de debate das humanidades possíveis, múltiplas, por inventar. Toda crítica, tão recorrente na obra de Artaud, sobre a arbitrariedade da palavra (como terreno preferencial do logos) se desfaz por esta nova compreensão do verbo-texto-fala como uma das atualizações possiveis, mas cujo "poder de ordem" se esvazia no refluxo da virtualização, e na assunção de todo conjunto não-dado de sentidos passíveis de serem levantados nessa dinâmica de interfaces multi-projecionais de linguagem. A matéria do texto não é mais um fim, um produto (ou o melhor produto), um receptáculo, uma voz uníssona, um discurso fechado, um local fixo de trabalho. Ela é o desenho específico, provisório, dinâmico, vivo, e somente vivo porque em trânsito criativo ininterrupto com todas as linguagens possíveis no campo virtual múltiplo do plano de composição.

Uma pequena mudança de olhar, mas que talvez carregue em si um deslocamento perceptivo interessante para o trabalho do dramaturgo. Compreender o texto como a ponta de um iceberg para alem das associações consciente-inconsciente; que não existe dramaturgia-pro- duto e dramaturgia-processo, posto que toda dramaturgia devém do jogo possível de cada processo, e escolhendo falar de alguns assuntos, fala ainda mais alto de tudo o que não diz. Cada processo de criação especifica e singulariza as linhas de força e densidades que definem uma forma de atualização de linguagem dramatúrgica e não outra, e é pela análise precisamente de tais especificidades que a dramaturgia como campo disciplinar de trabalho pode ser melhor pensada na contemporaneidade. Como um platô dos possíveis, que, escapando velozmente dos limites que configuram essa possibilidade, desdobra devires poderosos, pelos quais permanece possível, precisamente, $\mathrm{o}$ ato contínuo da criação. 


\section{REFERÊNCIAS}

DELEUZE, Gilles. Literatura e Vida. São Paulo: Editora 34, 1997.

. Lógica do Sentido. Trad. Luís Roberto Salinas Fortes. São Paulo: Perspectiva, 2000.

GIL, José. O Espaço Interior. Lisboa: Editorial Presença, 1993.

A Imagem-Nua a as Pequenas Percepções - Estética e Metafenomenologia. Lisboa: Relógio D’Água Editores, 2005.

LEHMANN, Hans-Thies.Teatro Pós Dramático. Trad: Pedro Sussekind. São Paulo: Cosac \& Naïf, 2007.

SARRAZAC, Jean-Pierre. A Invenção da Teatralidade. Porto: Deriva, 2009.

. Léxico do Drama Moderno e Contemporâneo. São Paulo: Cosac Naify, 2012.

. O Futuro do Drama. Porto: Campo das Letras, 2002.

SZONDI, Peter. Teoria do Drama Moderno. São Paulo: Cosac Naify, 2011. 